\title{
Antioxidant and Antimalarial Activity of Leea indica leaf extract against Malaria-mice Model
}

\author{
Erma Sulistyaningsih ${ }^{\mathrm{a}, \mathrm{b}_{*}}$, Talitha Yuni Amalia ${ }^{\mathrm{a}}$, Rizka Kartikasari ${ }^{\mathrm{a}}$ \\ ${ }^{a}$ Parasitology Department, Faculty of Medicine, University of Jember, Jember, Indonesia. \\ ${ }^{\mathrm{b}}$ Center for Development of Advanced Science and Technology, University of Jember, Jember, Indonesia.
}

\section{ARTICLE INFO \\ Article history: \\ Received on: 04/08/2017 \\ Accepted on: 19/09/2017 \\ Available online: $30 / 12 / 2017$}

Key words:

Antimalarial, antioxidant,

Leea indica, malaria-mice model.

\begin{abstract}
The increasing report on antimalarial resistance leads to the development of alternative drug from many resources. Leea indica is a medicinal plant traditionally used as an anti-malariaal agent in Indonesia. In this study we assessed the antioxidant as well as the antimalarial activity of $L$. indica. $L$. indica leaves were extracted in three different solvents (n-hexane, ethyl acetate, and methanol) and assessed for total phenolic, flavonoid and antioxidant activity. The antimalarial activity has been evaluated in malaria-mice model using the suppresive antimalarial assay. The highest fraction of total phenolic as well as total flavonoid was resulted from methanolic extract. It also demonstrated the strongest antioxidant activity with the $\mathrm{IC}_{50}$ of DPPH scavenging effect $1.62 \pm$ $0.02 \mu \mathrm{g} \mathrm{GAE} / \mathrm{ml}$ and the highest percentage of inhibition for hydroxyl radical, $57.60 \pm 2.52 \%$. Treatment with methanolic extract of $L$. indica 50,100 and $200 \mathrm{mg} / \mathrm{kg} \mathrm{BW}$ in malaria-mice models significantly $(\mathrm{P}<0.05)$ decreased the MDA and increased the SOD level. The methanolic extract decreased parasitaemia level by $3.50 \pm$ $1.26 \%$ on the day fourth and yielded $24.85 \pm 1.28 \%$ of suppression. The $L$. indica leaf extract showed an antioxidant activity and could be considered as antimalarial agent.
\end{abstract}

\section{INTRODUCTION}

Malaria is an infectious disease causing major health problem worldwide especially in tropical countries. There are approximately 1 million deaths each year due to malaria. Southeast Asia and Eastern Mediterranean countries are in the second highest prevalence of malaria after the African countries (WHO, 2010). It is a preventable and treatable parasite disease caused by Plasmodium parasites. The increasing reports on antimalarial drugs resistance lead to the need for development of new antimalarial agents from many resources (Rosenthal, 2003). One of the drug design strategy is based on the Plasmodium $s p$ sensitivity to oxidative stress (Duran-Bedolla,et al., 2013). Previous antimalarial agents was developed based on the disturbance of the parasite homeostasis balance resulting in

\footnotetext{
* Corresponding Author

Erma Sulistyaningsih, Medical Faculty, University of Jember, Jl. Kalimantan No. 37 Jember, Indonesia 68121. +62-331324446, +6289694995109, Fax: 0331-324446, sulistyaningsih.fk @ unej.ac.id.
}

parasite death, either by inducing accumulation of prooxidant molecules, by inhibiting antioxidant enzymes of the parasite or by producing reactive oxygen species (Duran-Bedolla, et al., 2013). It is known that an antimalarial agent that act as an inhibitor of the parasite antioxidant enzymes are potential in reducing parasitaemia but they also suppress host antioxidant enzymes (Pal and Bandyopadhyay, 2012).

Medicinal plants have been reported as the source of antimalarial drugs including Quinine and derivatives of Artemisinin (Batista et al., 2009). Therefore, screening of medicinal plants by in vitro and in vivo methods for their antioxidant and antimalarial activity will provide scientific evidence for developing new antimalarial agents. Leea indica, commonly known as Girang in Indonesia, is a plant which can be found in tropical as well as subtropical countries such as Indonesia, Malaysia, Thailand, and other Asian Countries. It is traditionally used by local residents in Indonesia as a natural remedy including malaria possibly due to its phenolic content which has potency as an antioxidant (Reddy et al., 2012). 
Several studies on $L$. indica extracts reported high activity of antioxidant and nitric oxide inhibitory effect (Saha et al., 2004), they were also indicating potent phosphodiesterase inhibitory activity (Temkitthawon et al., 2008). In this study, we reported the antioxidant as well as the antimalarial activity of $L$. indica through in vitro and in vivo in Plasmodium berghei-infected mice.

\section{MATERIALS AND METHODS}

\section{Collection of plant materials and extraction}

L. indica leaves were collected from Meru Betiri National Park, East Java, Indonesia. The plant material was identified by Meru Betiri National Park committee (No. BA.1271/BTNMB-1/2015). The fresh leaves plant were collected and shade dried which were later powdered and used for solvent extraction in three different polarity solvents, i.e. n-hexane, ethyl acetate and methanol. Extraction was started with non-polar solvent. The filtrate was evaporated by vacuum evaporator at $40^{\circ} \mathrm{C}$ to get $L$. indica extract from $n$-hexane. The residue was macerated again using ethyl acetate and methanol subsequently by similar method. The extraction yielded $3.2 \%$ for n-hexane (HG), $1.7 \%$ for ethyl acetate and $9.9 \%$ for methanol. The extracts were stored at $-20^{\circ} \mathrm{C}$ until they were used.

\section{Animal model and Ethical consideration}

The sample was male Balb/c mice of 1.5-2.5 months weighing 20-30 g. Samples were acclimatized to the laboratory conditions for a week. The study has received an ethical approval from The Research Ethical Committee of Medical Faculty University of Jember, in July 2016 (No. 886/H25.1.11/KE/2016).

\section{Total Phenolic and flavonoid concentration}

The content of total phenolic was assessed by spectrophotometric method i.e. Follin-Ciocalteu, and the absorbance was observed at $750 \mathrm{~nm}$. The content of total phenolic was calculated based on calibration curve which was made by gallic acid and expressed as milligrams of gallic acid equivalents (GAE) per $\mathrm{g}$ of sample. The concentration of total flavonoid was assessed by Aluminium Chloride $\left(\mathrm{AlCl}_{3}\right)$ colorimetric method and the absorbance was observed at $415 \mathrm{~nm}$. The total flavonoid content was calculated based on quercetin standard curve and expressed as mgs of quercetin equivalents (QE) per $\mathrm{g}$ of fraction.

\section{In vitro antioxidant activity}

Antioxidant activity of each extract was determined by three methods, i.e. 2,2'-diphenyl-1-picrylhydrazyl (DPPH), superoxide anion scavenging assay and hydroxyl radical scavenging assay. The result was compared with vitamin $\mathrm{C}$ as a positive control.

\section{DPPH method}

The scavenging activity of the fraction was determined by 2,2'-diphenyl-1-picrylhydrazyl (DPPH) method as previously described (Bursal and Gulcin, 2011). The absorbance was read at $517 \mathrm{~nm}$ and the parameter to analyse DPPH scavenging activity is Inhibitory Concentration $\left(\mathrm{IC}_{50}\right)$ value. $\mathrm{IC}_{50}$ is antioxidant activity based on concentration of extract which is need to inhibit the DPPH radical activity up to $50 \%$. $\mathrm{IC}_{50}$ value was resulted from linear regression equation between $\log$ of concentration and percentage of scavenging effect.

\section{Superoxide anion scavenging assay}

The scavenging activity on superoxide anion was measured by pyrogallol auto-oxidation. Slope of pyrogallol autooxidation was observed at $320 \mathrm{~nm}$. The scavenging activity on superoxide anion was calculated as percentage compared to control.

\section{Hydroxyl radical scavenging assay}

The scavenging activity on hydroxyl radical was measured by deoxyribose method (Fenton reaction) (Ilavarasan et al., 2005), where the absorbance was observed at $532 \mathrm{~nm}$. The scavenging activity on hydroxyl radical was calculated as percentage compared to control.

\section{Parasite inoculation}

The donor mice were Balb/c mice that were previously infected with $P$. berghei and had parasitaemia level of $10-15 \%$. The donor mice were euthanized, the blood was collected in EDTA-containing tube and added with RPMI-1640 to get a concentration of $1 \times 10^{7} \mathrm{P}$. berghei infected erythrocytes per $\mathrm{mL}$. As much as $2 \mathrm{~mL}$ diluted infected-blood was intraperitoneally injected to each mouse.

\section{In vivo antioxidant and antimalarial assay}

The antioxidant activity was also measured in vivo in malaria-mice models by measuring the level of lipid peroxidation by calculating the malondialdehyde (MDA) and the amount of superoxide dismutase (SOD). The antimalarial activity of $L$. indica was measured in vivo using the 4-day suppressive test as described previously (Peters et al., 1975).

\section{Administration of extracts}

The L. indica leaves extracts and Artemisine-based combination therapy (ACT) were solubilized in NaCMC $0.5 \%$. Positive control group received ACT $36.4 \mathrm{mg} / \mathrm{kgBW} /$ day, negative control group received $\mathrm{NaCMC} 0.5 \%$ and treatment groups received different dose of extracts $(50,100$ or $200 \mathrm{mg} / \mathrm{kgBW} /$ day $)$. Dosing were conducted orally, once daily, for 4 days after infection. Parasitaemia level was measured daily.

\section{Lipid peroxidation by MDA}

The Lipid peroxidation was measured by calculating thiobarbituric acid (TBA) reactivity as previously described (Buege and Aust, 1978). The plasma was mixed with phosphoric acid $10 \%$ and TBA $0.6 \%$, then incubated in boiling water for 45 
min. The sample was pretreated with butylatedhydroxytoluene (BHT) $20 \mu \mathrm{M}$. The absorbance was read at $532 \mathrm{~nm}$.

\section{Activity of superoxide dismutase (SOD)}

SOD activity was measured by pyrogallol auto-oxidation method. Erythrocyte lysate were added with $50 \mathrm{mM}$ Tris- $\mathrm{HCl}$ buffer $\mathrm{pH} 8.2$, 30mM EDTA and $2 \mathrm{nM}$ pyrogallol. The absorbance was read at $420 \mathrm{~nm}$ for $3 \mathrm{~min}$. The SOD activity was expressed as units/mg protein.

\section{Determination of parasitaemia and percentage suppression}

Thin blood smears were produced from tail blood daily. The blood smears were fixed in methanol and stained with $10 \%$ Giemsa at $\mathrm{pH}$ 7.2. The parasites were examined under microscope at 100x magnification power and oil immersion. The percentage parasitaemia was calculated by counting the infected erythrocytes in at least 1000 total erythrocytes. The percentage suppression of parasitaemia for each extract was calculated by the following equation:

$\%$ suppression $=[(\%$ parasitaemia in negative group $-\%$

parasitaemia in treatment group)/\% parasitaemia in negative group] X 100

\section{Data analysis}

Data was expressed as the mean \pm the standard deviation of each group. The statistical analysis was conducted using oneway analysis of variance (ANOVA) followed by Tukey's post hoc test. The results were considered significant if the value of $\mathrm{P}<$ 0.05 .

\section{RESULTS AND DISCUSSION}

\section{Concentration of Total Phenolic and flavonoid}

The extraction using three different solvents with different polarity yielded the methanol solvent as the highest resulted fraction, $267.56 \pm 2.01 \mathrm{mg} \mathrm{GAE} / \mathrm{g}$ for total phenolic and $101.90 \pm 3.24 \mathrm{mg} \mathrm{QE} / \mathrm{g}$ for total flavonoid, indicating that the polar constituent from $L$. indica leaf is higher than non-polar or semi-polar constituent. For each fraction, the total phenolic and flavonoid were determined as a base for analyzing the activity of antioxidant. The total phenolic and flavonoid content from each solvent can be seen in Table 1 .

Table 1: Total phenolic and flavonoid content of $L$. indica leaves extracts in three different solvents.

\begin{tabular}{lcc}
\hline \multicolumn{1}{c}{ Extract } & Total phenolic $(\mathbf{m g}$ & Total flavonoid (mg QE/g) \\
& GAE/g) & \\
\hline N-hexane & $5.27 \pm 0.19$ & $6.97 \pm 0.06$ \\
Ethyl acetate & $111.90 \pm 0.65$ & $25.96 \pm 1.48$ \\
Methanol & $267.56 \pm 2.01$ & $101.90 \pm 3.24$ \\
\hline
\end{tabular}

The polar methanolic extract had the highest phenolic concentration, compared to ethyl acetate extract and n-hexane extract. This result different with the previous study reported from Malaysia where the phenolic concentration of $19.15 \mathrm{mg}$ GAE/g from the ethanolic extract, $15.61 \mathrm{mg} \mathrm{GAE} / \mathrm{g}$ from ethyl acetate and
$1.29 \mathrm{mg}$ GAE/g from n-hexane extract (Reddy et al., 2012). Another study conducted in Bangladesh also reported differently (Rahman et al., 2012), indicating that there is a different in phenolic concentration in L. indica leaf. There are several factors affecting the phenolic compound of plant including the environmental condition such as climate, season, geographical condition, precipitation, temperature and land (Bouterfas et al., 2014). Phenolic compound is a secondary metabolite. This phytochemical compound occur ubiquitously in plants (Naczk and Shahidi, 2004). Plants phenolic compounds were divided into several categories, one of the most important is the flavonoid, so the pattern of flavonoid is similar with its total phenolic. The total flavonoid of $L$. indica leaf extract increased with the high polarity of the solvent. Methanolic extract resulted the highest total flavonoid, followed by ethyl acetate extract and the last n-hexane extract. Studies found that flavonoids are potent antioxidants (Nunes et al., 2012), they showed highly effective scavenger for most oxidizing molecules, such as singlet oxygen and free radicals (Bravo, 1998) which play a role in several diseases including malaria.

\section{In vitro antioxidant activity}

The three different $L$. indica extracts were tested for their activity as an antioxidant. The potency of antioxidant of the extract was measured by three different methods, i.e. DPPH method, superoxide anion scavenging assay and hydroxyl radical scavenging assay. The Inhibitor Concentration $\left(\mathrm{IC}_{50}\right)$ of DPPH scavenging effect of methanolic extract demonstrated the strongest antioxidant activity as compared to another extract, $1.62 \pm 0.02 \mu \mathrm{g}$ GAE/ml, as shown in Table 2.The DPPH assay works based on DPPH scavenging by an addition of a radical species or antioxidant. The reaction will decolourize the DPPH solution. Natural products can donate the electron which can be measured by DPPH through its colour change (Nunes et al., 2012) where the degree of colour bleaching is proportional to the content and potency of the antioxidants. A huge decrease of the absorbance indicates significant scavenging activity to free radical (Krishnaiah et al., 2011). Among all fractions tested, methanolic extract had the highest inhibition activity as shown by the lowest $\mathrm{IC}_{50}$ value. They also showed positively correlation with total phenolic content. The results implicated that the phytochemical compound in the plant extract which have capacity to donate hydrogen to a free radical could scavenge the potential damage due to the disease or other causes.

Table 2: Antioxidant activity of difference extracts of $L$. indica leaves.

\begin{tabular}{|c|c|c|c|}
\hline Test Sample & $\begin{array}{l}\text { DPPH IC } 50 \\
(\mu \mathrm{g} \\
\text { GAE/ml })\end{array}$ & $\begin{array}{l}\text { Superoxide } \\
\text { radical } \\
\text { scavenging } \\
\text { activity }(\%)\end{array}$ & $\begin{array}{l}\text { Hidroxyl radical } \\
\text { scavenging } \\
\text { activity }(\%)\end{array}$ \\
\hline N-hexane extract & $6.13 \pm 0.16$ & $16.94 \pm 0.33$ & $25.98 \pm 1.61$ \\
\hline $\begin{array}{l}\text { Ethyl acetate } \\
\text { extract }\end{array}$ & $2.83 \pm 0.04$ & $19.99 \pm 0.86$ & $43.23 \pm 1.92$ \\
\hline Methanol extract & $1.62 \pm 0.02$ & $12.64 \pm 0.45$ & $57.60 \pm 2.52$ \\
\hline Ascorbic acid & $2.32 \pm 0.07$ & $27.08 \pm 1.23$ & $53.73 \pm 2.35$ \\
\hline
\end{tabular}


Analysis of antioxidant activity by superoxide radical scavenging assay showed that the $L$. indica leaf methanolic extract had the lowest percentage of inhibition, $12.64 \pm 0.45 \%$ compared to another extract, as shown in Table 2. Superoxide anion is a weak oxidant, but it is an important biological source of reactive oxygen species (ROS). It can increase production of powerful and hazardous hydroxyl radicals and singlet oxygen, both of which contribute to the development of oxidative stress (Alves et al., 2010). Our study revealed that the methanolic extract had the highest total phenolic and flavonoid compounds but had the lowest superoxide scavenging activity. Phenolic and flavonoid are polar phytochemicals, the high polarity can cause high reactivity leading to decrease of slope reaction at the beginning of reaction and increase slope reaction at the midle to the end of reaction, arguing that superoxide scavenging activity of methanolic extract is the lowest compared to another extract.

The study also demonstrated that the $L$. indica methanolic extract had the highest percentage inhibition for hydroxyl radical, $57.60 \pm 2.52 \%$ compared to another extract. Hydroxyl radical is one of the potent ROS. It is an important species in various pathological processes and can damage molecule of biological system and play a role in carcinogenesis, mutagenesis and cytotoxicity (Babu et al., 2001) due to its capacity to react with polyunsaturated fatty acid in cell membrane phospholipids (Khan et al., 2012). The hydroxyl radical was generated by the reaction of $\mathrm{H}_{2} \mathrm{O}_{2}$ and the ferrous that would react with 2-deoxyribose. Another study also reported that in an extract, the hydroxyl radical scavenging activity is equivalent to its antioxidant activity which is represented by the decrease intensity of red colour (Gulcin et al., 2005). In this study, methanolic extract had the highest hydroxyl scavenging activity, better than the positive control vitamin $\mathrm{C}$. The antioxidant potency increases as the increase of the polarity of solvent, consistent with the total phenolic and flavonoid compounds, which exhibit an antioxidant capacity by blocking lipid free radicals or preventing degradation of hydroperoxides into free radicals (Soumaya et al., 2014). This result favors the methanolic extract for further study by analyzing its antimalarial potency.

\section{In vivo antioxidant assay and antimalarial activity}

In this study, antioxidant activity was also analyzed in vivo by measuring the MDA-level of peroxidation and the amount of SOD in malaria-mice model. As we know that MDA is an indicator of lipid peroxidation (Reis et al., 2010). After infection with $P$. berghei, mice were treated with methanolic extract of $L$. indica in dose of 50, 100 and $200 \mathrm{mg} / \mathrm{kg} \mathrm{BW}$. The result demonstrated that the extract significantly $(\mathrm{P}<0.05)$ decreased the blood MDA level and increased the blood SOD level. The higher dose of extract the lower the level of MDA, whereas the higher dose of extract the higher the level of SOD, even higher than positive control ACT (Table 3).

The negative control group showed the highest level of MDA, compared to positive control and treatment groups, concomitant with the lower of host's SOD activity. Those are important features of $P$. berghei infection (Iyawe and Onigbinde, 2006), where the oxidative stress occurs due to increase of MDA, not the decrease of antioxidant (Cabrales et al., 2011). The administration of the extract eliminated those features, the extract kept the ROS low therefore decreasing the $P$. berghei-induces lipid peroxidation resulted in lower MDA and consequently spare endogenous primary antioxidant enzymes reserves, such as SOD. The result also showed that positive control, an ACT-treated group, had lower SOD than treatment groups. As previously reported, artemisinin derivatives are prooxidant, they are inducers of free radical production (Haynes and Krishna, 2004), causing the use of SOD as an endogenous antioxidant enzyme resulting in the decrease of SOD.

Table 3: In vivo antioxidant and antimalarial activity of methanolic $L$. indica leaves extracts in $P$. berghei-infected mice.

\begin{tabular}{|c|c|c|c|}
\hline \multirow[b]{2}{*}{ Group } & \multicolumn{2}{|c|}{ In vivo antioxidant activity } & \multirow{2}{*}{$\begin{array}{c}\text { Percentage of } \\
\text { suppression } \\
\text { on day } 4(\%)\end{array}$} \\
\hline & $\operatorname{MDA}(\mu \mathrm{M})$ & $\begin{array}{l}\text { SOD } \\
\text { (units/ml) }\end{array}$ & \\
\hline Negative control & $58.15 \pm 3.87$ & $17.37 \pm 3.26$ & $0.00 \pm 0.00$ \\
\hline Dose $50 \mathrm{mg} / \mathrm{kgBW}$ & $39.11 \pm 4.57$ & $42.06 \pm 2.27$ & $12.32 \pm 1.65$ \\
\hline Dose $100 \mathrm{mg} / \mathrm{kgBW}$ & $38.15 \pm 3.98$ & $46.64 \pm 0.53$ & $18.92 \pm 1.33$ \\
\hline Dose $200 \mathrm{mg} / \mathrm{kgBW}$ & $35.48 \pm 3.22$ & $48.18 \pm 0.63$ & $24.85 \pm 1.28$ \\
\hline Positive control (ACT) & $32.00 \pm 4.07$ & $31.75 \pm 3.23$ & $50.17 \pm 2.89$ \\
\hline
\end{tabular}

This study also reports the in vivo antimalarial activity of the $L$. indica methanolic extract using the 4-day suppressive test. The $L$. indica extract reduced parasitaemia in a dose-dependent manner with $24.85 \pm 1.28 \%$ parasite suppression at a dose 200 $\mathrm{mg} / \mathrm{kg} \mathrm{BW}$, and there was a significant different of percentage parasitaemia between doses, with $\mathrm{P}<0.05$. But, the inhibition by ACT (positive control) was higher than those of all doses of extract (Fig. 1). It was suggested that antimalarial activity of the extract due to its phenolic compounds because they have an antioxidant activity. Previous studies have confirmed that the phenolic compounds show different extents of antimalarial activity (Ferreira et al., 2008; Boyomet al., 2009).

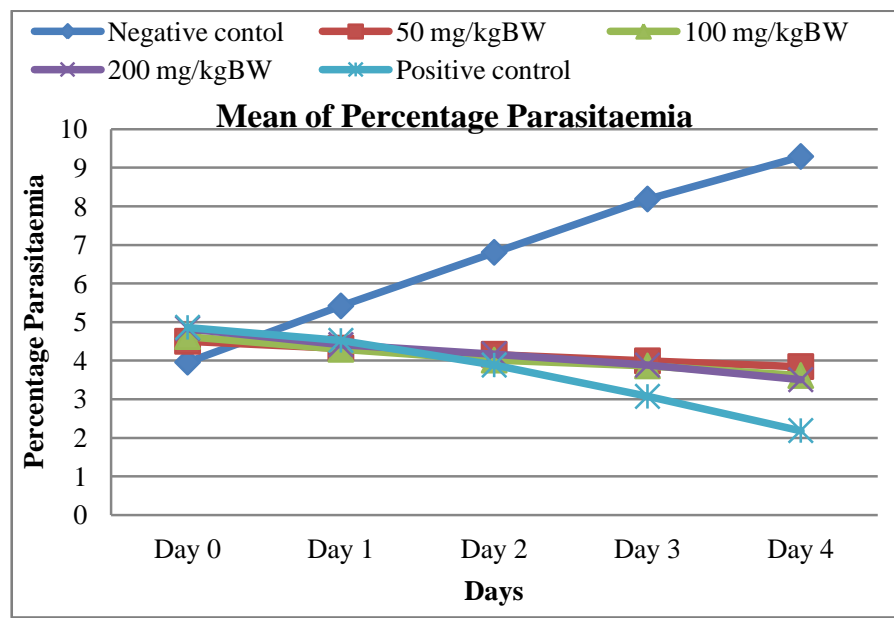

Fig 1: Mean of percentage parasitaemia for 5 days, before and after treatment. The parasitaemia was measured daily.

The idea of using an antioxidant as a therapy for malaria because the oxidative stress is considered plays an important role 
in the malaria pathogenesis. There are several hypothetical pathogenic mechanisms, including the parasite induction (Potter et al., 2005), the production of free radical (Keller et al, 2004) as well as antioxidant defenses (Sohail et al., 2007) by host cells to decrease the infection. In malaria pathogenesis, the oxidative stress are especially caused by the digestion of erythrocyte hemoglobin and production of heme within vacuoles, the translation of protein within the endoplasmic reticulum and the generation of the energy in the mitochondria, where the systems acts as antioxidant are ineffective on highly reactive free radicals, causing oxidative pathological processes. Condition of oxidative stress leads to damage of macromolecule cells including lipids and can induce lipid peroxidation in vivo causing degeneration of tissues. On the other hand, Plasmodium $s p$ is very sensitive to oxidative stress (Duran-Bedolla, et al., 2013), they are susceptible to free radicals and oxidant. An agent that exhibits high antioxidant capacity can promote an increase of total antioxidant capacity of host and decrease of lipid peroxidation, those changes are correlated with a significant reduction of parasitaemia (Silva, 2011; Gomes, 2011). Therefore, an antimalarial agent that act as an inhibitor of the parasite antioxidant enzymes is effective in decreasing parasitaemia (Pal and Bandyopadhyay, 2012).

\section{CONCLUSION}

Plants antioxidant properties have become an interest due to their potency to treat many diseases. In this study, among the three extracts, the methanolic extract of $L$. indica leaf has the strongest antioxidant activity where it is also showed the highest fraction for total phenolic and flavonoid compound, indicating that these compounds responsible for the high capacity of antioxidant. The methanolic L. indica leaf extract also showed potency as an antimalarial agent. Further research to identify the bioactive compound for this potency was needed for development a new antimalarial agent.

\section{Financial support and sponsorship: Nil.}

Conflict of Interests: There are no conflicts of interest.

\section{REFERENCES}

Alves CQ, David JM, David JP, Bahia MV, Aguiar RM. Methods for determination of in vitro antioxidant activity for extracts and organic compounds. Química Nova, 2010; 33:2202-2210.

Babu BH, Shylesh BS, Padikkala J. Antioxidant and hepatoprotective effect of Alanthusicicifocus.Fitoterapia, 2001; 72:272277.

Batista R, Junior SJA, Oliveira BA. Plant-derived antimalarial agents, new leads and efficient phytomedicines, part II, Non-alkaloidal natural products. Molecules, 2009; 14:3037-3072.

Bouterfas K, Mehdadi Z, Benmansour D, Khaled M, Bouterfas M, Latreche A. Optimization of Extraction Conditions of Some Phenolic Compounds from White Horehound (Marrubium vulgare L.) Leaves. Int J Org Chem, 2014; 4:292-308.

Boyom FF, Kemgne EM, Tepongning R, Mbacham WF, Tsamo E, Zollo PHA. Antiplasmodial activity of extracts from seven medicinal plants used in malaria treatment in Cameroon, J. Ethnopharmacol, 2009; 123:483-488.

Bravo L. Polyphenols: chemistry, dietary sources, metabolism and nutritional significance. Nutrit Rev, 1998; 56:317-333.

Buege JA, Aust SD. Microsomal lipid peroxidation. Methods Enzymol, 1978; 52:302-310.

Bursal E, Gulcin I. Polyphenol contents and in vitro antioxidant activities of lyophilized aqueous extract of kiwifruit (Actinidiadeliciosa). Food Res Int, 2011; 44:1482-1489.

Cabrales P, Zanini GM, Meays D, Frangos JA, Carvalho LJM. Nitric Oxide protection against murine cerebral malaria is associated with improved cerebral microcirculatory physiology. J Infect Dis, 2011; 203:1454-1463.

Duran-Bedolla J, Rodriguez MH, Saldana-Navor V, RivasArancibia S, Cerbon M, Rodriguez MC. Oxidative stress: production in several processes and organelles during Plasmodium sp development. OxidAntioxid Med Sci 2013; 2(2):93-100.

Ferreira A, Balla J, Jeney V, Balla G, Soares MP. A central role for free heme in the pathogenesis of severe malaria: the missing link. J Mol Med, 2008; 86:1097-1111.

Gomes BAQ. Efeitos da SuplementaçãocomAntioxidantesSobre as AlteraçõesOxidativasCerebrais e PulmonaresemMaláriaMurina. Master's Thesis, Federal University of Para, Belem, PA, Brazil, November 2011.

Gulcin I. Antioxidant activity of food constituents: an overview. Arc Toxicol, 2012; 86:345-391.

Haynes RK, Krishna S. Artemisinins: Activities and actions. Microbes Infect, 2004; 6:1339-1346.

Ilavarasan R, Mallika M, Venkataraman S. Anti-inflammation and antioxidant activities of Cassia fistula Linn.bark extracts. Afric J TradCompl Alt Med, 2005; 2:70-85.

Iyawe HOT, Onigbinde AO. Effect of chloroquine and ascorbic acid interaction on the oxidative stress of Plasmodium berghei infected mice. Int J Pharmacol, 2006; 2 (1):5-8.

Keller CC, Kremsner PG, Hittner JB, Misukonis M, Weinberg JB, Perkins DJ Elevated nitric oxide production in children with malarial anemia: Hemozoin-induced nitric oxide synthase type 2 transcripts and nitric oxide in blood mononuclear cells. Infect. Immun. 2004; 72:4868 4873.

Khan RA, Khan MR, Sahreen S, Ahmed M. Evaluation of phenolic contents and antioxidant activity of various solvent extracts of Sonchusasper (L.) Hill. Chemistry Central Journal, 2012; 6:12.

Krishnaiah D, Sarbatly R, Nithyanandam RR. A review of the antioxidant potential of medicinal plant species. Food Bioprod Process, 2011; 89:217-233.

Naczk M, Shahidi F. Extraction and analysis of phenolics in food.J Chrom A, 2004; 1054:95-111.

Nunes PX, Silva SF, Guedes RJ, Almeida S. 2012. Biological oxidations and antioxidant activity of natural products, In: Agricultural and Biological Sciences: Phytochemicals as Nutraceuticals - Global Approaches to Their Role in Nutrition and Health. VenketeshwerRao, CC BY 3.0 license.

Pal C, Bandyopadhyay U, Redox-active antiparasitic drugs. Antioxid Redox Signal, 2012; 17(4):555-582.

Peters WJ, Portus JH, Robinson BL. The chemotherapy of rodent malaria XXII. The value of drugresistant strains of P. berghei in screening for blood schizontisidal activity. Ann Trop Med Parasitol, 1975; 69:155-171.

Potter SM, Mitchell AJ, Cowden WB, Sanni LA, Dinauer M, Haan JB, Hunt NH. Phagocyte-derived reactive oxygen species do not influence the progression of murine blood-stage malaria infections. Infect Immun, 2005; 73:4941-4947.

Rahman MA, Imran T, Islam S. Antioxidative, Antimicrobial and Cytotoxic Effects of The Phenolics of Leea indica Leaf Extract. Saudi J Bio Sci, 2012; 213-225.

Reddy NS, Navanesan S, Sinniah SK, Wahab NA, Kae SS. Phenolic content, antioxidant effect and cytotoxic activity of Leea indica leaves. BMC Complement Altern Med, 2012; 12:128. 
Rosenthal JP. Antimalarial drug discovery, old and new approaches. J ExpBiol 2003; 206:3735-3744.

Saha K, Lajis NH, Israf DA, Hamzah AS, Khozirah S, Khamis S, Syahida A: Evaluation of antioxidant and nitric oxide inhibitory activities of selected Malaysian medicinal plants. J Ethnopharmacol 2004; 92:263-267.

Silva LD. Efeito da Suplementação com AntioxidantesSobre as AlteraçõesOxidativas e Produção de Interferon Gamma e Fator de NecroseTumoral Alfa emTecidoPulmonar de CamundongosInfectadospor Plasmodium Berghei. Master's Thesis, Federal University of Para, Belem, PA, Brazil, November 2011.

Sohail M, Kaul A, Raziuddin M, Adak T. Decreased glutathione-S-transferase activity: Diagnostic and protective role in vivax malaria. ClinBiochem, 2007; 40:377-382.

Soumaya KJ, Zied G, Nouha N, Mounira K, Kamel G, Genvieve FD, Leila GC. Evaluation of in vitro antioxidant and apoptotic activities of Cyperusrotundus. Asian Pac J Trop Med. 2014; 7(2):105-112.
Temkitthawon P, Viyoch J, Limpeanchob N, Pongamonkul W, Sirikul C, Kumpila A, Suwanborirux K, Ingkaninan K: Screening for phosphodiesterase inhibitory activity of Thai medicinal plants. J Ethnopharmacol 2008; 119:214-217.

World Health Organisation (WHO) 2010.World Malaria Report. Available at

http://www.who.int/malaria/world_malaria_report_2010/en/inde x.html

\section{How to cite this article:}

Sulistyaningsih E, Amalia TY, Kartikasari R. Antioxidant and Antimalarial Activity of Leea indica leaf extract against Malariamice Model. J App Pharm Sci, 2017; 7 (12): 163-168. 